\title{
Time Pressure, Time Saving And Online Shopping: Exploring A Contradiction
}

\author{
Pamela L. Alreck, Salisbury University, USA \\ Gerard R. DiBartolo, Salisbury University, USA \\ Memo Diriker, Salisbury University, USA \\ Howard F. Dover, Salisbury University, USA \\ Kirsten A. Passyn, Salisbury University, USA \\ Robert B. Settle, Salisbury University, USA
}

\begin{abstract}
Previous survey research revealed that consumers perceived online shopping and buying to be a time saving practice. Paradoxically, they only rarely reported using that tactic to save time, introducing a contradiction. Focus group research and unstructured interviews among active, time-pressured consumers provide partial solutions to the puzzle. Two types of online shopping benefits appeal to two types of consumers: Those experiencing situational time pressure respond well to "time-saving" appeals. Another, larger proportion, whose personal inclinations or personality traits result in time pressure are more interested in doing more tasks quickly or engaging in polychronic activities. These findings suggest online merchants simultaneously promote both time-saving and quicker accomplishment of more tasks. Though they are two sides of the same coin, time-pressured consumers tend to see only one side or the other. Both types of time-pressured shoppers eschew Websites requiring substantial "up-front" investment of time; complex, multi-option initial or home pages, and early insistence for "registration" that requires revealing personal information. This suggests clean, clear, uncluttered introductory pages and delay in urging registration until rapport has been established. Inexpensive, rapid delivery times and liberal return privileges were also highly valued by all time-pressured participants. Cost restrictions limit the degree to which online merchants can accommodate these preferences.
\end{abstract}

Keywords: Consumer Behavior, Electronic Commerce, Online Shopping, Time Pressure, Time Traits

\section{INTRODUCTION}

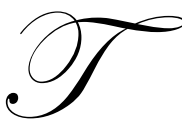

here are myriad reasons why people often say one thing and then do another. This is not an unfamiliar contradiction to marketers or survey researchers. Yet a strong relationship between the consumers' beliefs, attitudes or images, on the one hand, and their behavior in the marketplace, on the other, is at the very heart of self-reported research reliability and validity (Chamberlain and Broderick 2007). Survey research results are valueless, if not downright misleading, without a correspondence between verbal reports and actual behavior (Roisman, Holland et al. 2007). Because of this, discrepancies between images and actions demand exploration and, if possible, explanation.

\section{METHODOLOGY}

Survey research indicated that consumers, and especially "hurried consumers" viewed online shopping as an effective time-saving strategy (Alreck and Settle 2002). Nonetheless, those who perceived themselves as the most pressured for time did not report shopping online in order to save time, even though they typically thought online shopping would be a time-saver.

To resolve this puzzling contradiction, two focus group discussions were conducted, among locally recruited adult consumers, as well as 16 unstructured, one-on-one interviews. All the respondents participated 
voluntarily and were not compensated for their participation. The group discussions and personal interviews focused on the respondents' perceptions, images and beliefs about online shopping and the reasons for using that mode as much or as little as they did. The video records of the discussions and interviews were auditioned and interpreted by the researchers.

\section{SITUATIONAL TIME PRESSURE}

Perceived time pressure - the degree to which one perceives oneself as lacking time relative to the daily tasks of living - can be seen to arise from two, fairly distinct sources: One is situational, the other, personal (Settle and Alreck 1991). The most obvious cause and the one that is most easily identified and often cited is situational. People find themselves with too much work, too many things to do, and too little time to do them. Such timepressured individuals can, and often do document their situation by citing a litany of demands associated with their career, family, and affiliations (Lavin 1993).

Claims to be the victim of circumstances with regard to time pressure are very often legitimate. Anyone can see why parents of young children in a two-earner household, each working 40 hours or more a week, would be hurried, indeed. In fact, some people with no parental responsibilities and few formal occupational demands may occasionally find themselves pressed for time for reasons beyond their control (Sanik 1993).

\section{THE TIME/ACTIVITY EQUATION}

Rationing one's time is something of a balancing act between the time available for a given set of activities and the number of tasks and duration of time required to perform them. The term, "tasks" is used here in a very broad sense, including such things as eating, sleeping or recreation. Thus, increasing the number or duration of tasks in one area of life requires more time devoted to them and thus, less time for some other area (e.g., work more, sleep less) (Richbell and Kite 2007). But in total, activity level is the only variable in the equation because time is a constant. Each consumer has just 168 hours a week, no matter how much they might need more. So, overall, available time remains the same while activities have to be compressed, postponed, or expanded to equal the time available. Most consumers find their activities to be "self-expanding," if any time at all is available (Koiso-Kanttila 2005).

\section{PERSONAL TIME PRESSURE}

It was noted earlier that perceived time pressure can be seen to arise from two distinct sources: one situational, the other, personal. The situational sources of pressure assumes that time pressure results from circumstances imposing demands and impinging on one's time involuntarily. In other words, people are pressured for time because of earlier career choices, family life cycle stage, social commitments or personal obligations and the like - all very legitimate sources of situational time pressure. But this is certainly not the case for everyone.

A substantial portion of those who report feeling pressed for time "find themselves there" because they put themselves there by choice or inclination. The propensity to consistently engage in high levels of activity has been shown to be a durable personality factor (Settle and Alreck 1991). Such individuals require high levels of stimulation. They routinely take on more and more tasks and activities until, very literally, "their days are full." They tend to make commitments and accept obligations without much thought about when they will have time to satisfy them. In the persistent hustle and bustle of daily life, they sometimes "compress" time by engaging in polychronic activity, undertaking multiple tasks simultaneously (Cotte, Ratneshwar et al. 2004).

\section{TIME PRESSURE AND ONLINE SHOPPING}

Promoting online shopping as a time-saver is likely to be effective for those experiencing situational time pressure. Not so for those with personal time pressure. Those with situational pressure would almost certainly welcome anything that would reduce their activity level and the demands on their time. By contrast, those who experience time pressure because of their personal traits or inclinations are of a different ilk entirely. They seek 
activity and willingly increase their activity level. Thus, they are not likely to respond well to promotions or appeals that promise to reduce their level of activity (Alreck 1988).

This is not to say that those who seek high levels of activity, whether deliberately or unwittingly, will not find online shopping and buying appealing. It is just that it is not the time-saving aspect they value. It is important to recall that people of this type are prone to engage in polychronic activity. So, they are likely to watch TV while ironing, listen to a ball game while mowing the grass, or be cooking dinner, talking to a friend on the phone, and feeding the baby all at the same time (Lindquist and Kaufman-Scarborough 2004). The fact that they can shop online any time and from anyplace they have internet access might be very appealing because it allows them to shop while simultaneously engaged in other activities (Richbell and Kite 2007). This broader, "any time, any place" interpretation of online shopping convenience proved to be an important benefit for the majority of the online shopping survey respondents.

\section{INTERNET LEARNING CURVE}

There is really no adult learning curve for store shopping because it is something everyone learns to do from early childhood (Rust 1993; Anonymous 2005; Anonymous 2007). But for many adult consumers, there is a lot to learn about using the internet and Web. Even when that has been mastered, there is more to learn about shopping online. Our respondents reported they were somewhat intimidated by the complexity, or the anticipated complexity of shopping online (Zhou, Dai et al. 2007). Many consumers are completely undaunted by walking through the giant doors of a Super Walmart that carries many thousands of products and brands. Yet these same shoppers quickly become confused when viewing an online merchant's home page with only a few dozen menu items and links. Those who were not intimidated by the task nonetheless recognized it would take time to become familiar with online shopping, no matter how willingly and enthusiastically they approached the new venture (Kumar, Lang et al. 2004).

Like so many new tasks or procedures, online shopping requires at least a moderate "up front" investment in time and effort to develop proficiency in the long run. Those with low to medium levels of time pressure are better able to invest the time to learn than those who are extremely pressed for time. So, even though online shopping may save time in the long run, compared to conventional store shopping, expediency may demand that these consumers buy from stores and "postpone" (read procrastinate) learning to shop and buy online.

\section{THE IMPATIENCE FACTOR}

It would appear that the greater the consumers' time pressure, the more impatient they become. This is an inhibiting factor for online shopping. Because of the time required for shipping and delivery, online purchasing to meet a schedule or deadline requires planning in advance and the willingness to wait for arrival of the goods. Even when consumers are completely familiar with the online shopping and buying, they are not likely to shop online if they do not take time to plan ahead (Bosnjak, Galesic et al. 2007).

Many of the time-pressured consumers who were interviewed found shopping to be a chore, waited until the last minute to do it, and were anxious to "get it over with" as quickly and easily as possible. Under such circumstances, it is unlikely that many would take the time to initiate an online shopping session, even if they know how and could get timely delivery. One study highlighted the importance of delivery, reporting: "Customers perceptions of quality and satisfaction with online purchases depend upon three things: interaction with the Web site, delivery of the product and how prepared retailers are to address problems when they occur. Of the three, product delivery has the strongest influence on customers satisfaction and future purchase intentions (Collier and Bienstock 2006).

\section{RELUCTANCE TO RETURN GOODS}

Certainly there are times when goods must be returned to a conventional retail store; however, that may be less frequent because the customer can handle and inspect the goods, "try on" a garment or "try out" a piece of equipment. By contrast, online pictures and descriptions of merchandise - no matter how elaborate and complete- 
is a poor substitute, in the eyes of focus group participants, for the "hands on," in-store experience. Research indicates, "Consumers' initial lack of experiential information makes product choice more risky" (Wood 2001). Thus, online shopping is viewed as likely to result in the necessity for more returned goods than store shopping.

Although liberal return privileges are usually provided, the necessity to return goods for any reason can be costly in terms of time and effort. Those with the greatest time pressure are precisely those who would suffer the most in time lost. Consequently, high levels of time pressure may inhibit, rather than encourage online shopping for those concerned with the possibility the goods might have to be returned (Alreck and Settle 2001).

\section{ONLINE MARKETING IMPLICATIONS}

The information gleaned from the conversations and comments of interviewees and focus group participants centered on three aspects of online marketing and provide three types of suggestions regarding complexity, appeal, and return privileges.

\section{COMPLEXITY}

First and foremost, the respondents were more than a little put off by the complexity of online shopping and buying. They equated complexity with difficulty and simplicity with ease. All of them had at least limited experience with the internet and online shopping, and many had very substantial experience. Yet, they found the initial exposure with a new vendor's website to be more than a little daunting.

It was noted earlier that there are problems with the "learning curve" for online shopping, especially with very busy, time-pressured consumers. Their apprehension was heightened even further by the practice of many online marketers to require or at least to strongly urge that the buyer or even casual shopper "register" and perhaps create a so-called "my page" shortly after initiating contact. Obviously this is designed to customize the exposure to the characteristics and interests of the individual while providing information for an interactive marketing database: both important goals. But based on the results of this research, it is strongly recommend that this information gathering be postponed at lease until some sort of a tentative relationship has been established with the prospective customer (Kim and Ahn 2007; Smith and Shao 2007).

Beyond that, online marketers should avoid the temptation to "put everything in the front window." If a brick-and-mortar retail outlet attempted to put dozens of widely different kinds of stock on display in the show window, they would quickly recognize that "window shoppers" rarely lingered for long at the window or came into the store. Similarly, online marketers should resist the urge to show dozens of "sale" items on their home page in the hope that something will strike the fancy of a browsing consumer. Consumers in this study would rather be greeted by a simple Web presentation with a few, broad alternatives or channels directing them toward the kind of merchandise they seek or in which they have an interest. In the words of one respondent, "Why can't they show us something simple and attractive when we first arrive? Why all the clutter?"

\section{APPEALS}

It was noted earlier that, "time-saving" does not have much appeal to many time-pressured consumers because they are pressed for time by personal preference, rather than by situational factors. How, then, can online marketers benefit from time-saving as a positive attribute of online shopping? The answer lies mainly in the manner in which the appeal is expressed. Many time-scarce consumers are so because they are prone to try doing too much in too little time. Thus, the most effective appeal is not, "Save time shopping online!" but rather, "Get more done by shopping online." Doing stuff- undertaking activity - that is the hot button for this kind of consumer, and not saving anything, and especially time. These people are doers, not savers.

\section{RETURNS}

Return privileges are necessary to most successful online marketing efforts, but they are also very costly. Our respondents' suggestions regarding this aspect of online marketing held little potential for marketers because 
they were usually impractical. While some online sellers may be able to pay the package delivery costs for both sending goods and receiving returns, many would not be able to do so profitably. More importantly, the monetary loss is not what most concerns time-pressured buyers.

The majority of respondents felt the rapid delivery options-overnight or two-day air-were overpriced and the regular delivery alternative -5 to 7 business days - was too slow. They were of the opinion (though wrongly so) that marketers were "making money" off the faster delivery alternatives. Beyond that, they resented having to arrange and pay for return postage or package delivery. None understood the necessity for obtaining a "return merchandise authorization" (RMA) number and were entirely unwilling to pay "restocking" fees.

Online marketers may find it helpful to explore the cost and feasibility of auto-returns programs. While such facilities are appropriate for only a limited range of goods, they are very well regarded by consumers. These programs allow the dissatisfied buyer merely to reseal the package, attached the enclosed return label, and drop off the package or call the carrier for pick-up - cost free and no-hassle. In addition to saving the customer time and trouble, participants in this study indicated such programs revealed to them the sellers confidence in their goods and strong desire to satisfy their customers completely. A recent survey highlighted the positive possibilities inherent in effective handling of returns, noting: "Return represent an often-missed opportunity to manage customer relationships and build customer loyalty to the retailer." (Mollenkopf, Rabinovich et al. 2007).

\section{CONCLUSION}

In summary, this project revealed the following:

- Many consumers are pressed for time, not by their temporary circumstances, but by their persistent, personal tendency to undertake too much activity in too little time.

- Such consumers are prone to "compress" time by undertaking multiple activities, performing them simultaneously.

- The most effective online shopping appeal for such consumers is not to "save time" but to do more or to get more done!

- $\quad$ Consumers pressed for time, whether because of personal traits or situational factors, are reluctant to invest the "up-front" time to learn to shop online.

- When they do shop online, time-pressured consumers want to get on, get done, and get off with a minimum of time and effort.

- $\quad$ Online merchants who simultaneously promote both time-saving and quicker accomplishment of more tasks are likely to win more buyers than those focusing on only one of those benefits.

- Consumers often find their initial "home page" contact with online marketers overly complex, elaborate and confusing.

- Many consumers are reluctant to provide extensive "registration" information until they have established a simple relationship with the seller.

- $\quad$ Consumers pressed for time regret the necessity to wait for delivery of online purchases and are skeptical about the acceptability of the goods.

- $\quad$ Such consumers want a very liberal return policy and would appreciate the ability to return the goods without cost or difficulty.

Web software gives the online marketer the ability to monitor the number of hits and a host of additional, quantitative information about consumers browsing their sites. This monitoring ability is great for revealing the "what," but not very effective in disclosing the "who" and not at all helpful in gauging "why." Perhaps the main value of more qualitative, verbal research such as this project lies in furnishing some hints and suggestions about who responds to online marketing in a certain way and why they do so. 


\section{AUTHOR INFORMATION}

Pamela L. Alreck is an independent researcher and member of the Marketing Educators' Research Group, Perdue School of Business, Salisbury University. She earned her D.B.A. from United States International University.

Gerard R. DiBartolo is an Associate Professor of Marketing and a member of the Marketing Educators' Research Group, Perdue School of Business, Salisbury University. His Ph.D. is from George Washington University.

Memo Diriker is an Associate Professor of Marketing and a member of the Marketing Educators' Research Group, Perdue School of Business, Salisbury University. He earned his D.B.A. from Memphis State University.

Howard F. Dover is an Assistant Professor of Marketing and a member of the Marketing Educators' Research Group, Perdue School of Business, Salisbury University. He received his Ph.D. from University of Texas at Dallas.

Kirsten A. Passyn is an Assistant Professor of Marketing and a member of the Marketing Educators' Research Group, Perdue School of Business, Salisbury University. Her Ph.D. is from Pennsylvania State University.

Robert B. Settle is a Professor of Marketing and a member of the Marketing Educators' Research Group, Perdue School of Business, Salisbury University. He earned his Ph.D. from UCLA.

\section{REFERENCES}

1. Alreck, P. L. (1988). The Effect of Temporic Traits on Retail Buying. Retailing: It's Present and Future, Academy of Marketing Science and the American Collegiate Retailing Association.

2. Alreck, P. L. and R. B. Settle (2001). Consumer Attitudes Toward Returning Goods. Global Business Trends Contemporary Readings, Academy of Business Administration.

3. Alreck, P. L. and R. B. Settle (2002). "The hurried consumer: Time-saving perceptions of Internet and catalogue shopping." Journal of Database Marketing 10(1): 25.

4. $\quad$ Anonymous (2005). "Kids' wear moves back toward ... kids!" DSN Retailing Today 44(5): 18.

5. $\quad$ Anonymous (2007). "Young Shoppers Love Gift Cards." Chain Store Age 84(7): 152.

6. Bosnjak, M., M. Galesic, and T. Tuten (2007). "Personality determinants of online shopping: Explaining online purchase intentions using a hierarchical approach." Journal of Business Research 60(6): 597.

7. Chamberlain, L. and A. J. Broderick (2007). "The application of physiological observation methods to emotion research." Qualitative Market Research 10(2): 199.

8. Collier, J. E. and C. C. Bienstock (2006). "How Do Customers Judge Quality in an E-tailer?" MIT Sloan Management Review 48(1): 35.

9. Cotte, J., S. Ratneshwar and D. G. Mick (2004). "The Times of Their Lives: Phenomenological and Metaphorical Characteristics of Consumer Timestyles." Journal of Consumer Research 31(2): 333.

10. Kim, M. S. and J. H. Ahn (2007). "Management of trust in the e-marketplace: the role of the buyer's experience in building trust." Journal of Information Technology 22(2): 119.

11. Koiso-Kanttila, N. (2005). "Time, attention, authenticity and consumer benefits of the Web." Business Horizons 48(1): 63.

12. Kumar, N., K. R. Lang and Q. Peng (2004). "Consumer Search Behavior in Online Shopping Environments." E - Service Journal 3(3): 87.

13. Lavin, M. (1993). "Wive's employment, time pressure, and mail/phone order shopping - An exploratory study." Journal of Direct Marketing 7(1): 42.

14. Lindquist, J. D. and C. F. Kaufman-Scarborough (2004). "Polychronic tendency analysis: a new approach to understanding women's shopping behaviors." The Journal of Consumer Marketing 21(4/5): 332.

15. Mollenkopf, D. A., E. Rabinovich, T. M. Laseter and K. K. Boyer (2007). "Managing Internet Product Returns: A Focus on Effective Service Operations." Decision Sciences 38(2): 215.

16. Richbell, S. and V. Kite (2007). "Night shoppers in the "open 24 hours" supermarket: a profile." International Journal of Retail \& Distribution Management 35(1): 54. 
17. Roisman, G. I., A. Holland, K. Fortuna, R. C. Fraley (2007). "The Adult Attachment Interview and SelfReports of Attachment Style: An Empirical Rapprochement." Journal of Personality and Social Psychology 92(4): 678.

18. Rust, L. (1993). "Observations: Parents and children shopping together: A new." Journal of Advertising Research 33(4): 65.

19. Sanik, M. M. (1993). "The effects of time allocation on parental stress." Social Indicators Research 30(23): 175 .

20. Settle, R. B. and P. L. Alreck (1991). F-A-S-T: A Standardized Measure of Time Traits. Special Conference on Time and Consumer Behavior, Val-Morin, QC, Canada.

21. Smith, R. and J. Shao (2007). "Privacy and e-commerce: a consumer-centric perspective." Electronic Commerce Research 7(2): 89.

22. Wood, S. L. (2001). "Remote purchase environments: The influence of return policy leniency on two-stage decision processes." Journal of Marketing Research 38(2): 157.

23. Zhou, L., L. Dai and D. Zhang (2007). "Online Shopping Acceptance Model - a Critical Survey of Consumer Factors in Online Shopping." Journal of Electronic Commerce Research 8(1): 41.

\section{NOTES}




\section{NOTES}

